\title{
Phenolic Composition and Antioxidant Properties of Spireaea nipponica
}

\author{
Saban Keskin \\ Department of Chemistry, Faculty of Art and Science, \\ Bilecik Seyh Edebali University, Bilecik, Turkey \\ E-mail: sabankeskin61@hotmail.com \\ Yakup Sirin \\ Department of Chemistry, Faculty of Science, \\ Karadeniz Technical University, Trabzon, Turkey \\ E-mail: yakup.sirin@outlook.com \\ Hilal Ebru Cakir \\ Department of Chemistry, Faculty of Science, \\ Karadeniz Technical University, Trabzon, Turkey \\ E-mail: hilalebruhotaman@gmail.com \\ Gulsen Kaya \\ Petroleum Analysis Laboratory, Inonu University, Malatya, Turkey \\ E-mail: gulsen.kaya@inonu.edu.tr \\ Merve Keskin (Corresponding author) \\ Department of Chemistry, Faculty of Science, \\ Karadeniz Technical University, Trabzon, Turkey \\ E-mail: merveozdemirkeskin@gmail.com
}

\begin{abstract}
Spiraea nipponica is a plant belongs to the Rosaceae family. There are nearly one hundred species of spiraea plant. It can get longer as tall as 1.5 to $3 \mathrm{~m}$. The color of the flowers differ in species as white, red, pink and yellow. The leaf of the plant fall in winter season. Spiraea nipponica which blossomed early spring flowers without its leaf and the branch of the plant are seen as if they were covered in snow. That is why Spiraea nipponica is named as snow mound. In traditional medicine, root, leaf and fruit of the plant have been used as diuretic, analgesic and antitussive. Additionally, because of its essential oils the plant has antimicrobial and antifungal activity. Spiraea nipponica is the most abundant spiraea species in nature.

In this study, methanolic extracts of flower, leaf and branch of the plant were prepared and antioxidant capacity of these extracts were studied by using ferric reduction capacity (FRAP) and 2,2-diphenyl-1picrylhydrazyl (DPPH) methods. Total polyphenol concentration of extracts were determined by FolinCiocalteu method and Gallic acid as standard. Polyphenolic composition of the extracts were examined by HPLC-UV method as well. The flowers of $S$. nipponica were rich in vannilic acid, cinnamic acid, rutin and luteolin. A high correlation between antioxidant capacity and its total phenolic contents indicated that phenolic compounds were a major contributor of antioxidant activity of the plant.
\end{abstract}

Keywords: Spiraea nipponica, polyphenols, antioxidant capacity, phenolic composition

DOI: $10.7176 / J S T R / 5-2-10$ 


\title{
Spireaea nipponica'nın Fenolik Kompozisyonu ve Antioksidan Özellikleri
}

\begin{abstract}
Özet
Spiraea nipponica gül ailesine ait bit bitkidir. Spiraea bitkisinin yaklaşı yüz kadar türü bulunmaktadır. Boyu $1.5 \mathrm{~m}$ ile $3 \mathrm{~m}$ arasında değişmektedir. Bitkinin çiçeklerinin rengi bitkinin türüne göre değişmektedir ve beyaz, kırmızı, pembe ve sarı olabilmektedir. Kış mevsiminde bitkinin yaprakları düşer. Yapraksız erken ilkbaharda çiçek açan Spiraea nipponica görüntüsü ile bir kar yumağını andırmaktadır ve bu nedenle bitkiye kar yığını adı verilmektedir. Geleneksel ve tamamlayıcı tıpta bitkinin kökü, yaprağı ve meyvesi diuretik, analjezik ve antitussif olarak kullanılmaktadır. Ayrıca, uçucu yağlarından dolayı bitki antimikrobiyal ve antifungal aktiviteye sahiptir. . Spiraea nipponica doğada en çok bulunan spiraea türüdür.

Bu çalışmada, bitkinin yaprak, çiçek ve sap kısımlarının metanolik ekstraktları hazırlandı ve antioksidan aktivite tayinleri FRAP ve DPPH yöntemleri kullanılarak yapıldı. Toplam polifenol miktarı FolinCiocalteu metodu kullanılarak yapıldı ve standart olarak gallik asit kullanıldı. Ekstraktların fenolik kompozisyonu HPLC-UV kullanılarak belirlendi. S. nipponica çiçeklerinin vanilik asit, sinnamik asit, rutin ve luteolin açısından zengin olduğu görüldü. Antioksidan kapasite ve toplam polifenol miktarı arasındaki korelasyon, fenolik bileşenlerin bitkinin antioksidan kapasitesine önemli bir oranda katkısı olduğunu göstermektedir.
\end{abstract}

Anahtar Kelimeler: Spiraea nipponica, polifenoller, antioksidan kapasite, fenolik kompozisyon

\section{GíRiş}

Polifenoller; bitki dünyasının büyük bir kısmında bulunan, fitokimyasalların en geniş sınıflarından birini oluşturan ve insan yaşamında gerekli olan bileşiklerdir. Polifenoller güçlü antioksidanlardır ve aktiviteleri kimyasal yapılarına bağlıdır. Bu bileşikler antioksidan özelliklerinden dolayı kanser, kalp damar rahatsızlıkları, katarakt gibi hastalıklara yol açan, serbest radikallerin etkisiz hale getirilmesini sağlarlar. Fenolik bileşiklerin önemli kaynağını bitkiler oluşturur. Bitki polifenolleri çok fonksiyonlu olup, indirgeme aracı, hidrojen atomu verici ve singlet oksijen söndürücü olarak davranırlar. Bazı polifenoller ise metal iyonu şelatlama özelliklerine sahip antioksidanlar olarak etkilidirler (Rice-Evans vd., 1996).

İnsanlar tarafından tüketilen bitkiler farklı fenolik asit ve flavonoidler içerebilir. Bu nedenle bitkilerin fenolik içeriklerine bağlı olarak antioksidatif aktiviteleri oldukça ilgi çekici bir konu halini almıştır. Fenolik bileşenler indirgeyici ajanlar ve serbest radikal toplayıcılar olarak işlev görmektedir, bu nedenle fenolik bileşenler üzerine çalışmalar yapmak önem arz etmektedir (Saxena, vd., 2012).

Geleneksel ve tamamlayıcı tıpta önemli bir yer bulan fitoterapi ile ilgili yapılan çalışmalar kapsamında kullanılan bitkilerin çoğu doğada doğal olarak bulunmaktadır ve bitkilerin savunma sistemleri, çevre adaptasyonu gibi nedenlerle ürettikleri sekonder metabolitler insan sağlı̆̆ açısından önem arz etmektedir (Tatçı vd, 1999; Cecchini vd., 2007).

Çalışmamızda kullandığımız Spiraea nipponica (Şekil 1), tipik olarak 5-8 boyunda biraz daha geniş bir yayılıma sahip olan yoğun, dik, höyüklü, yaprak döken bir çalıdır. Shikoku, Japonya adasına özgüdür. Eliptik yaprakları obovat, üzeri açık yeşil, ancak yuvarlak dişli aplikler ile maviyeşildir. Yapraklar sonbaharda minimal olarak çekici bir sarıya dönüşür. Yuvarlatılmış yarım küre kümeleri küçük beyaz beş yapraklı çiçekleri erken ilkbaharda (Mayıs-Mayıs) geç ilkbaharda yaprakları kapsamaktadır.

Bu amaçla çalışmamızda Spiraea nipponica bitkisinin yaprak, çiçek ve sap kısımlarının antioksidan özellikleri ve fenolik bileşenleri belirlendi. 

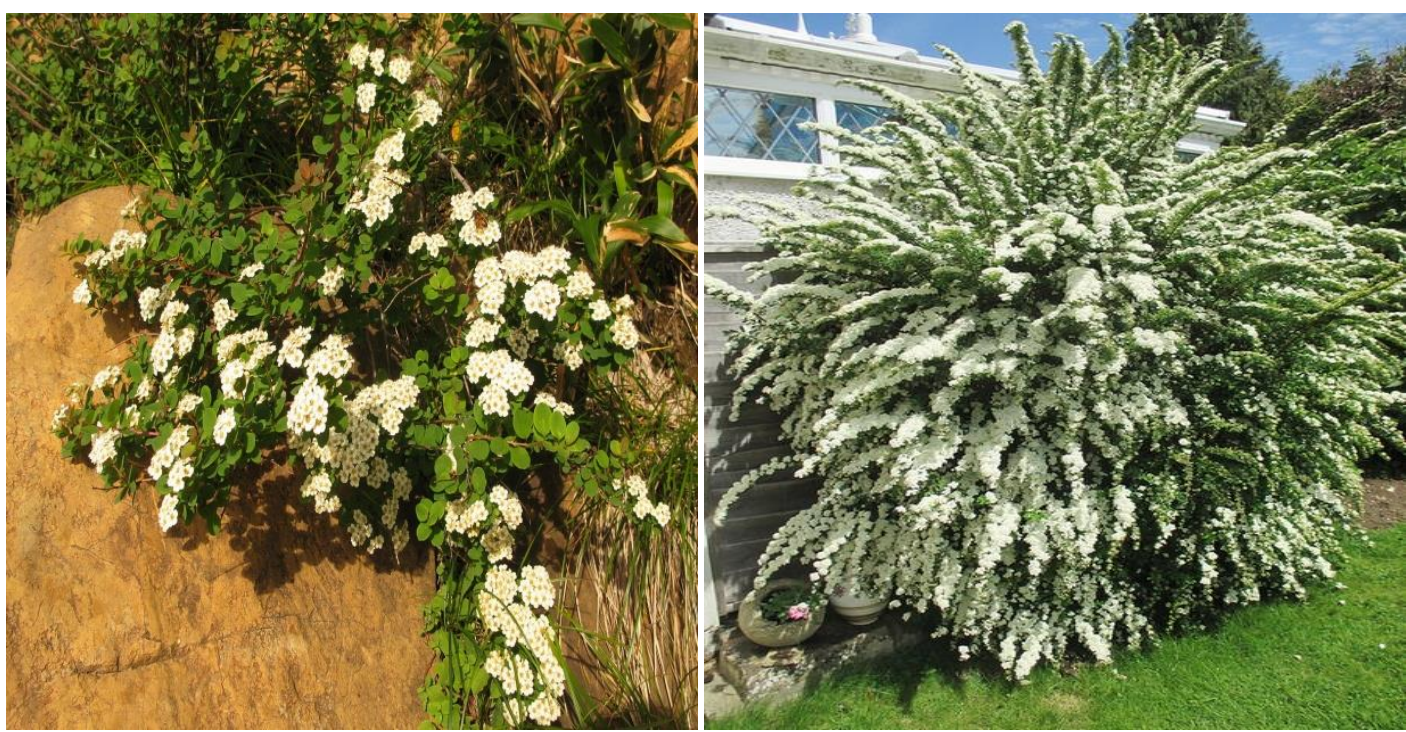

Şekil 1. Spiraea nipponica

\section{MATERYAL METOT}

\subsection{Numunelerin Temini ve Ekstraktların Eldesi}

Spirea nipponica bitkisi 2017 bahar döneminde toplandı. Bitkinin farklı bölgelerine ait (yaprak, sap, çiçek) kısımlardan metanolik ekstraktlar hazırlandı. Bu amaçla numuneler kurutuldu, öğütüldü ve her bir kısımdan yaklaşık 3'er gram tartıldı. Daha sonra üzerine \%99' luk metanol ilave edildi ve 24 saat boyunca çalkalandı. İşlem tamamlandıktan sonra karışım süzüldü ve çözelti hacmi belirlendi.

\subsection{Toplam Fenolik Madde Miktarı}

Doğal ürünlerde toplam fenolik madde ölçümü için en çok kullanılan yöntem olan Folin Ciocalteu metodu, bileşenlerin Folin Ciocalteu reaktifi ile renkli kompleks oluşturması esasına dayanır (Singleton ve Rossi, 1965; Singleton vd., 1999). Bu reaktifin aktif merkezinde Mo(VI) bulunur. Fenolik maddelerin folin reaktifi ile oluşturduğu mor menekşe renkli kompleks 765 nm'de maksimum absorbansa sahiptir. Bu rengin spektrofotometrik ölçümü ile toplam fenolik madde miktarı tespit edilir.

Gallik asit (GA) standardı kullanılarak kalibrasyon grafiği hazırlandı (Slinkard vd., 1977; Singleton ve Rossi, 1965). Gallik asitin farklı konsantrasyonlarda $\left(1,0 ; 0,5 ; 0,25 ; 0,125 ; 0,0625\right.$ ve $\left.0,03125 \mathrm{mg} \cdot \mathrm{mL}^{-1}\right)$ çözeltileri hazırlandı. Konsantrasyona karşılık ölçülen absorbans değerleri ile standart grafiği çizildi. Çizilen grafiğe göre ekstrakların toplam fenolik madde miktarı ayrı ayrı hesaplandı. Sonuçlar mg GAE/ $\mathrm{g}$ cinsinden ifade edildi.

\subsection{Toplam Flavanoid Tayini}

Flavonoid miktarı tayini Fukumoto ve Mazza (2000)'ya göre yapıldı. Alüminyum klorür kolorimetrik yöntemi olarak da adlandırılan bu metodun prensibi, alüminyum klorürün, flavonoidlerin 4-keto ve C-3 ya da C-5 (ya da her ikisi) hidroksil grubu ile kararlı bir asit kompleksinin oluşturulmasına dayanmaktadır. Alüminyum klorür ayrıca flavonoidlerin A ve B halkalarındaki orto-dihidroksil grupları ile kararsız bir asit kompleksi de oluşturur (Pallab vd., 2013). Standart olarak farklı konsatrasyonlarda $\left(0,25 ; 0,125 ; 0,0625 ; 0,03125 ; 0,015625\right.$ ve $\left.0,0078125 \mathrm{mg} \cdot \mathrm{mL}^{-1}\right)$ kuersetin (KE) kullanıldı. Pipetlemeler bittikten 40 dakika sonra $415 \mathrm{~nm}$ ' de saf suya karşı tüplerin absorbansları kaydedildi. Konsantrasyona karşılık kaydedilen absorbans değerleri ile standart grafiği çizildi. Çizilen standart grafiğgine göre ekstrakların toplam flavanoid madde miktarı hesaplandı ve toplam flavanoid miktarı mg KE/g cinsinden ifade edildi.

\subsection{Antioksidan Kapasitesi Tayini}

Spirea nipponica'nın yaprak, sap ve çiçeklerinden hazırlanan metanolik ekstraktların antioksidan kapasiteleri demir indirgeme (FRAP) ve serbest radikal süpürme (DPPH) yöntemleri kullanılarak yapıldı (Keskin vd., 2019).

89| P a g e

www.iiste.org 


\subsubsection{Demir İndirgeme Gücü (FRAP)}

$\mathrm{Bu}$ yöntemin ilkesi, $\mathrm{Fe}^{3+}$ iyonlarının, asidik ortamda $\mathrm{Fe}(\mathrm{TPTZ})^{3+}$ tripriridiltriazin kompleksiyle antioksidanlar tarafindan mavi renkli Fe (TPTZ) ${ }^{2+}$ kompleksine indirgenmesine dayanır (Benzie and Strain, 1999). FRAP reaktifi, $40 \mathrm{mM} \mathrm{HCL}, 2.5 \mathrm{~mL} \mathrm{FeCl} 3.6 \mathrm{H}_{2} 0$ ve $25 \mathrm{~mL} 300 \mathrm{mM}$ pH 3.60 asetat tamponunda çözündürülmüş $2.5 \mathrm{~mL} 10 \mathrm{mM}$ TPTZ karıştırılarak hazırlandı. $3 \mathrm{~mL}$ taze hazırlanmış FRAP reaktifine $100 \mu \mathrm{L}$ örnek eklenmiş, daha sonra $37^{\circ} \mathrm{C}$ 'de 4 dakika inkübe edilmiştir. Numunelerin absorbansı damıtılmış su referansına karşı 593 nm'de kaydedilmiştir. Trolox referans standardı olarak kullanıldı. FRAP testiyle elde edilen sonuçlar, $100 \mathrm{~g}$ numune başına $\mu \mathrm{M}$ demir eşdeğeri Fe (II) olarak verildi.

\subsubsection{Serbest Radikal Süpürme Kapasitesi (DPPH)}

Metanol ekstraktlarının radikal süpürme kapasitesi, Molyneux tarafindan açıklanan DPPH yöntemi kullanılarak belirlendi (Molyneux, 2004). Her örnek için, altı farklı konsantrasyonda $0.75 \mathrm{~mL}$ ekstrakt metanol içinde $0,75 \mathrm{~mL} 0,1 \mathrm{mM}$ DPPH ile karıştıııldı ve $50^{\circ} \mathrm{C}$ sıcaklıkta oda sıcaklığında inkübasyondan sonra absorbans $517 \mathrm{~nm}$ 'de kaydedildi. Sonuçlar, SC50 (mL başına mg numune) olarak ifade edildi; bu, DPPH'nin \% 50 temizlenmesine neden olan her bir numunenin konsantrasyonunu ifade etmektedir.

\subsection{Fenolik Komposizyonun Belirlenmesi}

HPLC-UV analizleri iki dalga boyunda ( $280 \mathrm{ve} 315 \mathrm{~nm}$ ) aynı anda cevap alınabilen UV-Vis dedektör ile donanımlı Thermo Finnigan Surveyor HPLC sisteminde yapıldı. Analizler ters faz C18 kolonu (150 mm $\mathrm{x} 4.6 \mathrm{~mm}, 5 \mu \mathrm{m}$; Fortis) kullanarak ve asetonitril, su ve asetik asitle gradient program uygulanarak gerçekleştirildi (De Villers vd., 2004). Ayrıca numune ve standartların enjeksiyon hacmi $25 \mu \mathrm{L}$ 'ye, mobil faz akış hızı $1,2 \mathrm{~mL} \cdot \mathrm{dk}^{-1}$ ya ve kolon sicaklığı kolon firınında $30{ }^{0} \mathrm{C}^{\prime}$ ye ayarlanarak çalışma optimizasyonu sağlandı (Can vd., 2015).

\section{BULGULAR}

Spirea nipponica' nın yaprak, sap ve çiçeklerinden hazırlanan metanolik ekstraktların toplam polifenol miktarı sirasiyla $5.45 \mathrm{mg}$ GAE.g ${ }^{-1}, 3.55 \mathrm{mg}$ GAE. $\mathrm{g}^{-1} \mathrm{ve} 4.75 \mathrm{mg} \mathrm{GAE}^{-1}$; demir indirgeme kapasitesi sirasiyla $11.03 \mu \mathrm{M} \mathrm{FeSO} 4.7 \mathrm{H}_{2} \mathrm{O} . \mathrm{g}^{-1}, 9.09 \mu \mathrm{M} \mathrm{FeSO}_{4} .7 \mathrm{H}_{2} \mathrm{O} . \mathrm{g}^{-1}$ ve $10.61 \mu \mathrm{M} \mathrm{FeSO}_{4} .7 \mathrm{H}_{2} \mathrm{O} . \mathrm{g}^{-1}$; serbest radikal temizleme kapasitesi $\left(\mathrm{SC}_{50}\right)$ sirasiyla $2.28 \mathrm{mg} \cdot \mathrm{mL}^{-1}, 3.06 \mathrm{mg} \cdot \mathrm{mL}^{-1} \mathrm{ve} 4.12 \mathrm{mg} \cdot \mathrm{mL}^{-1}$ olarak belirlendi. Bitkinin yapraklarının vanilik asit, kafeik asit, epikateşin, p- kumarik asit, ferulik asit, rutin, daidzein, sinnamik asit ve luteolin içerdiği tespit edildi. Vanilik asit, epikateşin, p- kumarik asit, rutin, daidzein, sinnamik asit ve luteolinin ise bitkinin her üç kısmında da olduğu belirlendi. Analiz sonuçları Tablo 1 ve Tablo 2' de özetlendi.

Tablo 1. Spirea nipponica yaprak, çiçek ve sap kısımlarının toplam polifenol ve antioksidan değerleri

\begin{tabular}{|c|c|c|c|}
\hline & $\begin{array}{c}\text { Toplam Polifenol } \\
\left.\text { Miktarı (mg GAE.g }{ }^{-1}\right)\end{array}$ & $\begin{array}{l}\text { Toplam Antioksidan Kapasite, } \\
\text { FRAP }\left(\mu \mathrm{M} \mathrm{FeSO}{ }_{4} .7 \mathrm{H}_{2} \mathrm{O}^{-1}{ }^{-1}\right)\end{array}$ & $\begin{array}{c}\text { Serbest Radikal } \\
\text { Süpürme Kapasitesi } \\
\left(\mathrm{SC}_{50} \mathrm{mg}^{-\mathrm{mL}^{-1}}\right)\end{array}$ \\
\hline Yaprak & $5.45 \pm 0.02$ & $11.03 \pm 0.04$ & $2.28 \pm 0.03$ \\
\hline Çiçek & $4.75 \pm 0.00$ & $10.61 \pm 0.00$ & $4.12 \pm 0.05$ \\
\hline Sap & $3.55 \pm 0.00$ & $9.09 \pm 0.07$ & $3.06 \pm 0.08$ \\
\hline
\end{tabular}


Tablo 2. Spirea nipponica yaprak, çiçek ve sap kısımlarının fenolik komposizyonu

\begin{tabular}{|c|c|c|c|c|c|c|c|c|c|c|c|c|c|c|}
\hline \multicolumn{10}{|c|}{ Fenolik Kompozisyon (mg fenolik bileşen.g $\left.{ }^{-1}\right)^{*}$} \\
\hline & GA & PKA & p-BA & KT & VA & KA & ŞA & EKT & p-CA & FA & RT & DA & SA & LT \\
\hline Yaprak & - & - & - & - & 71.96 & 14.27 & - & 11.86 & 31.98 & 14.11 & 98.57 & 35.47 & 114.10 & 150.05 \\
\hline Çiçek & - & - & 8.59 & - & 618.40 & 8.80 & 1.90 & 33.60 & 6.63 & - & 65.60 & 32.50 & 489.65 & 59.50 \\
\hline Sap & - & - & - & - & 14.21 & - & 0.17 & 4.76 & 9.82 & 2.98 & 156.77 & 12.75 & 78.27 & 54.93 \\
\hline
\end{tabular}

GA: Gallik asit, PKA: Protokatequik asit, p- BA: p- Benzoik asit, KT: Kateşin, VA: Vanilik asit, KA: kafeik asit, ŞA: Şiringik asit, EKT: Epikateşin, p-CA: p-Kumarik asit, FA: Ferullik asit, RT: Rutin, DA: Daidzein, SA: Sinnamik asit, LT: Luteolin

*Analiz sonuçları üç tekrarlı olarak elde edilmiştir. Standart sapma $<0,01$ olduğu için tablo değerlerine yansitılmamıştır.

\section{TARTIŞMA}

Geleneksel ve tamamlayıcı tıbbın yaygınlaşması ile fitoterapik önemi olan bitkilerin çeşitli amaçlarla kullanımı artmıştır. Bu amaçla kullanılan bitkiler yapılarında bulunan sekonder metabolit olarak adlandırılan flavonoidler açısından zengindir. Bu bileşenler ile bitki antioksidan özellik kazanarak serbest radikallerden kaynaklanan oksidatif stresin etkilerinin azalmasına vesile olmaktadır (Harakotr vd., 2014). $\mathrm{Bu}$ çalışma ile Spirea nipponica'nın farklı kısımları (yaprak, sap ve çiçek) bazı fenolik asitler ve flavonoidler açısından incelenmiştir. Literatürde Spirea nipponica'nın polifenolik kompozisyonu ile alakalı yapılmış çok fazla çalışma bulunmamaktadır. Farklı spirea türlerine ait çalışmalarda elde edilen sonuçlar ile kıyaslandığında çalışmamızın bulguları bu bulgular ile benzerlik göstermektedir.

Karpova ve arkadaşlarının (2015) yapmış olduğu çalışmada farklı Spirea türlerinin toplam polifenol miktarının \%3 ile \%7 arasında değiştiği ve bu bileşenlerin \%1-2 oranında flavanoidlerden oluştuğu ifade edilmektedir. Elansary ve arkadaşları (2016) yapmış oldukları çalışmada bitkinin yaprak kısmının polifenolik bileşenlerce zengin olduğu ifade edilmiştir. Deniz yosunlarında elde edilen ekstrakt (SWE) ile muamele edildiğinde bitkinin yaprak kısmının toplam polifenol ve flavonoid içeriğinin $\operatorname{arttığ~}$ bildirilmiştir. Kostikova ve Shaldaeva (2017) tarafından yürütülen bir çalışmada Rusya'nın uzak doğu bölgesinde yetişen farklı spirea türlerinin yaprak kısımlarından elde edilen ekstraktlar polifenolik bileşenler ve antioksidan aktivite açısından incelendiği bildirilmiştir. Farklı spirea türlerinin yaprak kısımlarının suda çözünebilen polifenolik antioksidan bileşenlerce zengin olduğu araştırmacılarca ifade edilmektedir.

\section{SONUÇ}

Fenolik bileşenler açısından oldukça zengin olan Spirea nipponica' nın oldukça iyi antioksidan kapasiteye sahip olduğu görüldü. Epikateşin, sinnamik asit gibi önemli fenolik bileşenleri içeren bitkinin antioksidanları açısından Geleneksel ve Tamamlayıcı Tıp alanında kullanılabileceği ifade edilebilir. Ayrıca bitkinin sap, yaprak ve çiçek kısımlarından elde edilecek antioksidan bileşenler (fenolik asitler ve flavonoidler) gıdalarda katkı maddesi olarak kullanılması gıdaların fonksiyonelleşmesini arttıracağı açıktır.

\section{References}

Benzie, I.F.F. \& Strain, J.J., (1999). Ferric reducing/antioxidant power assay: direct measure of total antioxidant activity of biological fluids and modified version for simultaneous measurement of total antioxidant power and ascorbic acid concentration. Methods in Enzymology, 299, 15-27. 
Can, Z., et. al., (2015). An investigation of Turkish honeys: Their physico-chemical properties, antioxidant capacities and phenolic profiles, Food Chemistry, 180, 133-141.

Cecchini C, Cresci A,Coman MM \& Ricciutelli M., (2007). Antimicrobial activity of seven Hypericum entities from central Italy, Planta Med, 73, 564-6.

De Villiers, et.al., (2004). Development of A Solid-Phase Extraction Procedure for the Simultaneous Determination of Polyphenols, Organic Acids and Sugars in Wine, Chromatographia, 59, 403409.

Elansary, H.O., Skalicka-Wozniak, K. \& King, I,W., (2016). Enhancing stress growth traits as well as phytochemical and antioxidant contents of Spiraea and Pittosporum under seaweed extract treatments, Plant Physiology and Biochemistry, 105, 310-320.

Fukumoto L. R. ve Mazza, G. (2000). Assessing antioxidant and prooxidant activities of phenolic compounds, Journal Agriculture Food Chemistry, 48, 3597-3604.

Harakotr, B., et. al., (2014). Anthocyanin, phenolics and antioxidant activity changes in purple waxy corn as affected by traditional cooking, Food Chemistry, 164 510-517

Karpova, E.A., \& Lepteva, N.P., (2015) . Phenolic compounds in taxonomy of the genus Spiraea L., Ukrainian Journal of Ecology.

Keskin, Ş. et. al. (2019). An investigation of Humulus lupulus L.: Phenolic composition, antioxidant capacity and inhibition properties of clinically important enzymes, South African Journal of Botany, 120, 170-174.

Kostikova, VA. \& Shaldaeva, TM. (2017). The Antioxidant Activity of the Russian Far East representatives of the Spiraea L. (Rosaceae Juss.) Genus. Russian Journal of Bioorganic Chemistry, 43(7), 790-794.

Molyneux, P. (2004). The use of the stable free radical diphenylpicrylhydrazyl (DPPH) for estimating antioxidant activity. Songklanakarin Journal of Science and Technology 26, 211-219

Rice-Evans, C.A., Miller, N.J. \& Paganga, G., (1996). Structure-antioxidant activity relationships of flavonoids and phenolic acids, Free Radical Biology \& Medicine, 20 (7), 933-956.

Saxena, M., Saxena, J. \& Pradhan, A. (2012). Flavonoids And Phenolic Acids As Antioxidants In Plants And Human Health, Int. J. Pharm. Sci. Rev. Res., 16(2), 130-134

Singleton V. L. ve Rossi J. A., (1965). Colorimetry of Total Phenolics with PhosphomolybdicPhosphotungstic Acid Reagents, American Journal of Enology and Viticulture, 16, 144-158.

Singleton, V. L., Orthofer R. ve Lamuela-Raventos R. M., (1999). Analysis of Total Phenols and Other Oxidation Substrates and Antioxidants by Means of Folin-Ciocalteu Reagent, Methods in Enzymology, 299, 152-178.

Slinkard, K. \& Singleton, V.L., (1977). Total phenol analysis: automation and comparison with manual methods. American Journal of Enology and Viticulture 28, 49-55.

Pallab, K., et. al., (2013). Estimation of Total Flavonoids Content (TFC) And Antioxidant Activities of Methanolic Whole Plant Extract of Biophytum Sensitivum Linn., Journal of Drug Delivery \& Therapeutics, 3, 4, 33-37.

Tatçı Ç, Şimşek S, Şengül M \& Gez S., (1999). Teucrium chamaedrys ve Plantago major L.'nin antimikrobiyal aktiviteleri, I. Babadağ Sempozyumu, Bildiri Metinleri Kitabı PAÜ Yay., 117-124. 